\title{
The Influence of Peer Pressure on College Students and the Countermeasures
}

\author{
Ziyu Chen ${ }^{1, \dagger}$, Yazhi Deng ${ }^{2, *}, \dagger$ \\ ${ }^{1}$ Guangzhou University Affiliated High School, Guangzhou, China, 510000 \\ ${ }^{2}$ Vanke Meisha Academy, Shenzhen, China, 518000 \\ ${ }^{*}$ Corresponding author.Email:2dengyazhi@stu.vma.edu.cn \\ ${ }^{\dagger}$ These authors contributed equally.
}

\begin{abstract}
With the pressure of competition becoming more and more intense, the phenomenon of peer pressure among college students became more and more common in our daily life, not only about our work but also about our studies. However, some college students believed that peer pressure had harmed them. This had sparked public concern and became the focus of society. This review further explored the dissertation research on the effects of peer pressure on college students from previous years. This paper analyzed the influencing factors of peer pressure on college students, such as gender, the family environment, and grade, and the methods for college students to reduce peer pressure. In conclusion, we were looking forward to a diverse and comprehensive study of peer pressure.
\end{abstract}

Keywords: peer pressure, college students, positive impact, negative impact.

\section{INTRODUCTION}

Peer pressure refers to a change in behavior that tends to conform to peer norms as individuals feel the influence of peer groups on their attitudes. When a person stays in a peer group, the different kinds of people will bring lots of pressure on each person $[1,2]$.

Many reasons will result in peer pressure, gender, the study grade, the family environment. Peer pressure is invisible and has a strong influence on individual behavior. Peer pressure is also producing both positive and negative effects. Peer pressure will trigger some unhealthy competition. The positive side can be summarized as peer pressure is common among college school students who are of similar age. It is mainly manifested in the fierce competition in the process of learning. The negative effect will result in giving up learning, psychological inferiority, blindly follow, losing self-esteem, and other behavioral tendencies.

The peer pressure of college students is multiple-level, each group has different pressure, such as social, professional, urban, and rural. This paper is just talking about the reasons for the peer pressure on college students, and it is still limited and does not conduct a comprehensive study on peer pressure and we do not discuss the different sides of the peer pressure. We hope we can fill the gap in the future [3].

Many factors can contribute to peer pressure. For example, gender, family environment, grade level, etc. When each person's views and behaviors do not always match those of the group, they feel peer pressure to conform when their views conflict with the ideas or behaviors of group members. There are two sides to everything, so there are positive and negative sides to peer pressure. Positive peer pressure will help us improve our performance and help us make some improvements. Negative peer pressure can weaken our self-confidence and self-esteem and make us feel anxious.

In this study, we analyzed peer pressure and explored the factors and effects of peer pressure. We also explored how to respond appropriately to peer pressure, and different approaches to reducing the negative effects of peer pressure.

\section{INFLUENCE FACTOR}

\subsection{Factor Influencing Peer Pressure}

Many factors can contribute to peer pressure. Gender, family environment, and one's grades are all causes of peer pressure. 
If college students choose a major without too many people of the same gender, everyone will feel lonely because there are no friends of the same gender around them and they are not willing to let themselves make friends with people of other genders, and they will feel a lot of pressure when facing this situation. In "Gender Stress of Preschool Male Students," Zhao, who is the main character, feels worried and anxious about the study and employment environment because he thinks there are not enough men in this major [3].

Family environment can affect gender differences in personality traits of college students. Improving the family environment is important for promoting the formation of a good human personalities and maintaining the mental health of children. The model of family education should take into full consideration the differences in the influence of the family environment on the personality traits of children. The role of parents' emotional attitude in guiding children's personality is very obvious [3]. The psychological development of a person, the formation of personality traits, and the family environment in which he lives, and the emotional attitude with parents and children have a direct link, in this regard, the American psychologist Nosh has the following vivid description: "Children learn to blame in an environment of criticism; in a hostile environment, learn to fight. In an environment of ridicule, learn to blame themselves; in an environment of encouragement, learn to be confident; in an environment of fairness, learn to be just; in an environment of safety, learn to trust; in an environment of approval, learn to love themselves; in an environment of humiliation, learn to feel guilty ........" [4].

Academic stress is an internal and external pressure that is beyond a student's ability or that may threaten him or her. How can stress be handled properly? Stress can be both a motivator and a resistance to learning. It is not only an important factor in mental health but also an important variable in academic performance. Many students suffer from academic stress, they are anxious and nervous. Sometimes, academic stress can promote students to learn and motivate them to study hard. This may help them to get a good grade. On the contrary, sometimes students just feel stressed, but they don't try hard or just make some effort unconsciously. This will cause them to get more and more stress and will make them more and more anxious. The pros and cons of college students' academic stress on their learning and growth depend on how they handle it [4].

\subsubsection{Positive Impact}

Sometimes the peer pressure on the college students may have a positive effect on them. When they stay in a peer group, they will compare to others automatically. If the group and individual develop in the same direction, the higher the cohesion of the group, the more motivated individuals will have to move forward, which is the group's promotion to individuals. Most college students can deal with the pressure properly. They can drive themselves in a good way and put in a lot of effort. Sometimes the peer pressure can help them get a good grade or achieve some improvement, promote the development of their interests and hobbies, and improve their adaptability to an unfamiliar environment. With the pressure of competition becoming more and more intense, the phenomenon of peer pressure among college students become more and more common in our daily life, not only about our work but also about our study.

However, some college students believe that peer pressure has harmed them. This has sparked public concern and become the focus of society. This review further explores the dissertation research on the effects of peer pressure on college students from previous years. This paper analyzes the influencing factors of peer pressure on college students, such as gender, the family environment, and grade. and the methods for college students to reduce peer pressure. We are looking for ways to address the negative effects of peer pressure, both externally and internally. This review only discusses peer pressure on college students, and it doesn't include social peer pressure. There are still many gaps to be filled in this area. In conclusion, we are looking forward to a diverse and comprehensive study of peer pressure. When you are new to a new environment and facing unfamiliar people and things, everyone is under a certain amount of pressure. It may come from good classmates and strict teachers.

But in university life, there is all the interpersonal pressure that comes from peers, as everyone tries to find good friends and get acquainted with the people around them more quickly. The pressure they bring can also allow students to fit in better. Sometimes, family reasons can also cause peer pressure on students. If the gap between rich and poor is too wide it can put a lot of pressure on some students, and if some families have different education and philosophies it can also put a lot of pressure on students. But if students think they are not rich enough, they will study harder for scholarships, take their studies more seriously to get a good job or take parttime jobs on campus to earn more pocket money. All of these will give students exercise and promote their better development. If you feel that your family philosophy is not compatible and you feel some pressure between students, you can also learn good practices and habits from others so that we can all get along more amicably.

\subsubsection{Negative Impact}

There is much reason will lead to peer pressure, such as the grade, the family, the gender. If the peer pressure is too much that the college students can offer it, it will lead to series of bad consequences, for example, they will become anxious and lose their self-esteem. They can't keep pace with the group, they will get anxious and 
gradually lose confidence. If the students in the group that have bad values and behavior are not conducive to the socialization of college students.If some students in the class are particularly good at their grades, other students will feel inferior or sad because of this. Then the pressure from the grades can affect the students' mindset and some of them may simply give up trying because the disparity is too great and go down the wrong path from then on.

Of course, some students may also feel inferior and sensitive because of the wide gap between the rich and the poor in their families. They feel that they are not rich enough, but spending time with other people regularly puts a lot of pressure on them and they want to live the same life like them, but if they are unable to achieve such a standard of living and are overly inferior and sensitive, they may resort to some unscrupulous means to acquire some unjust possessions. Peer pressure will make students follow the herd mindlessly. Such as stealing, robbery, etc. This series of bad behaviors can have a significant negative impact on students. To get into the group as soon as possible, they often change themselves and act as cater to the group members. After a period, the college students will lose the ability to judge right and lose their self-confidence $[2,5]$.

\section{THE WAY TO REDUCE PEER PRESSURE}

Different people have different ways to reduce the pressure. However, not all solutions can be helpful for everyone. The following solutions would provide help for teenagers to reduce their pressure in two ways.

\subsection{Internal Method}

The internal approach focuses on addressing the negative effects of stress through self-awareness, value building, and level of stress resistance. In the face of psychological stress, if the stimulus (stress) to which the individual is subjected is in some way contradictory to his or her abilities, needs, and motivations, the impact of the stimulus (stress) on the individual is small. However, if the individual believes that his needs can be met, the stimulus (stress) has a low impact on the individual. When the individual is faced with this stimulus (pressure), he or she will take positive measures to face it [6]. Similarly, when adolescents are faced with peer pressure and the pressure meets the needs of the adolescent, the adolescent will take positive measures to cope with it. Therefore, adolescents should establish the right values and have the right positive personal consciousness so that they will take positive measures when facing peer pressure.

Secondly, giving adolescents an adequate and objective understanding and knowledge of peer pressure can also empower them to overcome peer pressure [1]. When college students experience anxiety, depression, or other negative emotions, they can try meditating in a quiet environment. When meditating, students can consider asking themselves about their personal feelings, such as whether the extra study will really help them in their future development, and what their expectations and plans for the future are [6]. Students may consider recording their questions and feelings during meditation, and then take them out when they feel upset or stressed. Do not deny yourself because you have not surpassed others or have not been affirmed by others. One should be clear about one's future plans and path. When walking according to your own plan and direction, you will not be negatively affected by peer pressure. They will walk in their plans and directions and will not be influenced by peer pressure. They will not have the problem of inferiority complex caused by peer pressure.

\subsection{External Method}

The external approach is to address the negative effects of stress mainly through the external influence on stress and mindfulness.

For long-term reducing peer pressure methods, the factors that make the peer pressure bring out negative effects are important. Family is an important factor that affects a person's degree of stress resistance. According to research parents' education level would impact the teenagers' degree of stress resistance. If parents' education level is low, teenagers usually take a negative response [7, 8]. Thus, improving parents' education level can also improve teenagers' degree of stress resistance [9]. In this case, parents should take some courses to let them know the correct way to educate children.

The external approach focuses on external distractions and distractions to address adverse emotions such as anxiety and irritability caused by stress. Following is the ways to reduce peer pressure. Exercise is to some extent able to stimulate neurons to secrete dopamine thus making people who exercise feel happy. According to research doing exercise can reduce certain depression, anxiety, and stress [10]. Thus, teenagers should be encouraged to do exercises to release the pressure.

Music therapy can also relieve negative emotions caused by stress. According to research, listening to positive music can give people positive cues and indirectly help them to think positively. On the contrary, listening to depressing and sad songs can also give people a negative suggestion. Therefore, college students should listen to positive and cheerful music more often and listen to sad music less often to help them reduce their negative emotions to a certain extent. [11] Besides, music therapy can also help college students improve their selfconfidence and find themselves. College students are learning new skills in the process of being exposed to music, and in the process they are able to tap into their 
potential strengths. [11] When their potential strengths are discovered, they become more sure of themselves and receive their affirmation. This in a way creates a comfortable environment for them to relax and get pleasure from music.

\section{CONCLUSION}

In conclusion, peer pressure is a double-edged sword, which may be able to bring motivation to adolescents, and excessive pressure may also cause adolescents to lose confidence and become anxious, etc. The right way to deal with peer pressure is to let teenagers understand and deal with peer pressure properly in order to enhance their resilience. Teens also need to develop their own perspective to help them see stress as motivation rather than anxiety in the face of stress. The literature does not address how music therapy should be used properly. Since music therapy is of a more specialized nature, professional help is definitely needed. This has a key role in the use of music therapy.

This review still has some limits. This review only discusses academic peer pressure, but didn' $t$ include social peer pressure. Social peer pressure includes peer leading others to do some bad behaviors, like drugs, drinking, and so on. Those behaviors are also happening in our life frequently, and it is also important for teenagers to grow. Thus, in the future, there should be more research and reviews based on social peer pressure to help us know deeper about how social peer pressure impacts teenagers, so that can reduce the peer to lead other teenagers to do a bad thing. In addition to the above, we also need to expand on the proper way to use music therapy in order to help college students relieve stress properly. If the correct music therapy approach is not used, it may not work or have the opposite effect. Future research directions could strengthen the methods of operant therapy.

\section{REFERENCES}

[1] Xie, Yue-Ying. Peer pressure and coping strategies in adolescent "peer groups"[J]. Mental Health Education in Primary and Secondary Schools, 2007, 000(007):19-20.

[2] Zhang Rong, Yang Fang. A study on the problem of peer pressure among college students in the perspective of ideological and political education[J]. Contemporary Tourism, 2018(7):262-262.

[3] Xiao Sanrong, Xu Guangxing. Family environment influences gender differences in adolescent personality traits[J]. Psychological Inquiry, 2009, 29(002):71-75.

[4] Zhang Bo. Research on the negative influence of peer groups on the character of junior high school students[D]. Guangxi Normal University, 2016.
[5] Yang Man-Li, Yang Xiao-Hua. Exploration of the role of peer pressure on teaching booster[J]. Guangxi Education (Secondary Education), 2017(7).

[6] Cheng Liying. An analysis of the adjustment methods of college students' psychological stress[J]. Science and Education, 2008(30):27-28

[7] Wang Yaning. (2011). Reducing Students' psychological pressure and maintaining students' mental Health. Ningxia Education, 000(007), 147147.

[8] Xiangtan University. (2018). The Impact of parents' educational level on children's overeducation. (Dissertation, Xiangtan University).

[9] Xie Dongbei, \& Zhong Fufu. (2008). Experimental Study on the Effect of Physical Exercise on College Students' mental sub-health. Chinese Journal of Practical Medicine (30), 207-208.

[10] CLASEN, D. R., \& BROWN, B. B. (1987). Understanding peer pressure in the middle school. Middle School Journal, 19(1), 21-23.

[11] Sha Tao, Meng Ning. Journal of Shanxi Datong University (Natural Science Edition), 201,37(04):122-124 